\title{
Pengaruh relationship marketing terhadap loyalitas konsumen pada Rumah Makan Patene di Makassar
}

\author{
Lisa Jolanda Catherine Polimpung \\ Fakultas Ekonomi Program Magister Manajemen Universitas Katolik Parahyangan \\ Jl. Merdeka No. 30, Babakan Ciamis, Kec. Sumur Bandung, Kota Bandung, Jawa Barat \\ Kode Pos 40117, Indonesia \\ lisapolimpung0117@gmail.com
}

Submitted: Aug 07, 2020; Reviewed: Aug 09, 2020; Accepted: Aug 28, 2020

\begin{abstract}
Currently the world has entered globalization where this has led to many changes that have occurred in the aspect of life where competition in the industrial world is also getting tougher. Patene Restaurant in Makassar is a restaurant where you can feel the competition that is happening in the world today. This study analyzes the effect of relationship marketing input, namely understanding customer expectations, building service partnerships, and total quality management on the loyalty of consumers at Patene Restaurant in Makassar. The number of respondents was 211 respondents where the respondents filled out the questionnaire distributed by the researcher. This study found that the relationship marketing input applied by Patene Restaurant in Makassar has a significant effect on consumer loyalty at Patene Restaurant.
\end{abstract}

Keywords: building service partnership; consumer loyalty; total quality management; understanding customer expectation

Abstrak: Saat ini dunia telah memasuki globalisasi di mana hal ini menyebabkan banyaknya perubahan yang terjadi di dalam segi kehidupan di mana persaingan di dunia industri juga semakin ketat. Rumah Makan Patene di Makassar merupakan rumah makan di mana ikut merasakan persaingan yang terjadi di dunia sekarang ini. Penelitian ini menganalisis pengaruh relationship marketing input, yakni understanding customer expectation, building service partnership, dan total quality management terhadap loyalitas yang dimiliki oleh konsumen Rumah Makan Patene di Makassar. Jumlah responden yakni sebanyak 211 orang responden di mana responden mengisi kuesioner yang dibagikan oleh peneliti. Penelitian ini menemukan bahwa relationship marketing input yang diterapkan oleh Rumah Makan Patene di Makassar memiliki pengaruh yang signifikan terhadap loyalitas Konsumen Rumah Makan Patene.

Kata kunci: building service partnership; loyalitas konsumen; total quality management; understanding customer expectation

\section{PENDAHULUAN}

Pengaruh globalisasi dunia menyebabkan terjadinya banyak perubahan di segala segi kehidupan, termasuk di dalamnya adalah persaingan di dunia industri yang kini menjadi semakin ketat dan penuh dengan kompetisi (kompasiana.com). Konsumen memiliki nilai tuntutan yang besar serta beragam. Hal ini dikarenakan dengan semakin banyaknya perusahaan yang ada, maka pilihan yang ditawarkan kepada 
konsumen juga semakin banyak, sehingga hal ini menyebabkan mereka dapat segera beralih ke perusahaan pesaing apabila kualitas produk di mata konsumen buruk. Kualitas produk merupakan kapabilitas dari suatu produk dalam melaksanakan manfaat atau kegunaannya di mana mencakup kedaya tahanan, keunggulan, akurasi, kemudahan, proses dan perbaikan, serta atribut-atribut lainnya (Kotler \& Armstrong, 2016). Namun, hanya dengan menciptakan produk yang berkualitas saja tidaklah cukup, karena meskipun perusahaan dapat memeroleh konsumen dengan cara ini, perusahaan belum tentu dapat memertahankan loyalitas konsumen terhadapnya.

Konsumen dapat dikatakan loyal apabila konsumen tersebut selalu kembali membeli produk atau jasa dari provider atau penyedia jasa di tempat yang sama dan juga memelihara sebuah sikap yang positif untuk di masa yang akan datang terhadap produk maupun penyedia jasa tersebut (Borneo \& Sutopo, 2011). Tanpa adanya loyalitas, maka konsumen dapat dengan mudah berpaling kepada perusahaanperusahaan pesaing yang ada. Loyalitas konsumen adalah sebuah dorongan sikap dalam melakukan transaksi secara berulang (Tangkilisan, 2013). Loyalitas konsumen dapat diperoleh dengan cara menetapkan relationship marketing di mana berdasarkan penelitian yang dilakukan oleh Evans \& Laskin (1994), konsumen akan cenderung memertahankan hubungan jangka panjang pada suatu perusahaan yang menerapkan relationship marketing dan melakukan pembelian secara berulang terhadap produk yang ditawarkan perusahaan tersebut. Relationship marketing adalah metode atau prosedur di mana perusahaan membangun kerja sama jangka panjang dengan konsumen dan calon konsumen, dan bekerja sama agar dapat mencapai satu tujuan yang telah ditentukan (Evans \& Laskin, 1994). Relationship marketing memiliki tujuan yakni untuk menciptakan hubungan yang dapat saling memuaskan antara konsumen, pemasok, dan distributor di mana untuk menjaga bisnis dan preferensi dalam jangka waktu yang lama atau panjang (Kotler \& Keller, 2014). Relationship marketing memiliki empat variabel yang memengaruhi loyalitas konsumen, yaitu Understanding Customer Expectation (UCE), Building Service Partnership (BSP), Total Quality Management (TQM), Empowering Employees (EE) (Evans \& Laskin, 1994).

Understanding Customer Expectation (UCE) adalah suatu aktivitas di mana perusahaan merekognisi keinginan-keinginan atau harapan-harapan yang dimiliki oleh konsumen dan memasarkan produk maupun jasa sesuai dengan yang diinginkan atau diharapkan oleh konsumen (Anwar, 2016). Building Service Partnership (BSP) adalah sebuah kerja sama yang terbentuk ketika perusahaan bekerja sama dengan konsumen dan menambahkan customer service yang diinginkan oleh konsumen ke dalam penawaran mereka (Evans \& Laskin, 1994). Menurut Sarim, Setiawan, \& Freddy (2013), building service partnership adalah suatu kerja sama yang dilakukan oleh perusahaan bersama konsumen untuk menambahkan pelayanan yang diinginkan konsumen.

Total Quality Management (TQM) adalah sebuah usaha dalam membentuk kualitas perusahaan secara keseluruhan mulai dari produsen hingga konsumen (Sarim dkk., 2013). Evans \& Laskin (1994) menjelaskan total quality management sebagai sebuah usaha yang digunakan untuk mencapai keuntungan kompetitif dengan secara terus menerus berusaha untuk meningkatkan segala yang ada di dalam perusahaan. Empowering Employees (EE) adalah membiarkan karyawan memiliki kebebasan dan kreativitas dalam menyelesaikan masalah yang dimiliki oleh konsumen (Evans \& Laskin, 1994).

Rumah Makan Patene di Makassar merupakan rumah makan yang merupakan usaha milik keluarga yang mana telah mengimplementasikan relationship marketing di dalam menjalankan usahanya. Namun berdasarkan wawancara yang dilakukan kepada pemilik Rumah Makan Patene, jumlah konsumen semakin lama semakin menurun beberapa tahun belakangan. Variabel relationship marketing yang diterapkan oleh Rumah Makan Patene sendiri mencakup Understanding Customer Expectation (UCE), Building Service Partnership (BSP), Total Quality Management (TQM), dan tidak mencakup Empowering Employement (EE) di mana karyawan di Rumah Makan Patene tidak diberikan kebebasan di dalam menyelesaikan masalah yang dihadapi dengan konsumen secara langsung, melainkan karyawan selalu bertanya kepada pemilik rumah makan apabila terdapat masalah dengan konsumen, oleh karena itu peneliti tidak memasukkan empowering employement ke dalam variabel yang diteliti.

Dalam penelitian yang dilakukan oleh Evans \& Laskin (1994); Purwanto (2015); Borneo \& Sutopo (2011); dan Fakhrudin (2018), seluruh variabel yang terdapat relationship marketing memiliki pengaruh terhadap loyalitas konsumen. Berbeda dengan penelitian yang dilakukan oleh Haruna (1997) dan Rahmawati (2016) di mana di dalam penelitiannya menemukan bahwa understanding customer expectations tidak memiliki pengaruh terhadap loyalitas konsumen. 
Penelitian yang dilakukan oleh Junistyaningrum \& Sugiarto (2016) mengenai pengaruh implementasi relationship marketing terhadap customer loyalty, mengukur dua variabel di dalam relationship marketing, yakni building service partnership dan total quality management. Penelitian yang dilakukan oleh Saputri, Yaningwati, \& Fanani (2013), di mana meneliti dua variabel di dalam relationship marketing, yakni understanding customer expectations dan building service partnership terhadap loyalitas konsumen dengan pertimbangan bahwa perusahaan yang diteliti tidak menerapkan variabel relationship marketing input lainnya di dalam perusahaannya. Melalui penelitian yang dilakukan oleh Junistyaningrum \& Sugiarto (2016), ditemukan bahwa building service partnership dan total quality management memiliki pengaruh terhadap loyalitas konsumen. Penelitian yang dilakukan oleh Saputri dkk. (2013) menemukan bahwa understanding customer expectations dan building service partnership memiliki pengaruh terhadap loyalitas konsumen.

Adanya perbedaan di dalam hasil penelitian yang dilakukan sebelumnya memunculkan pertanyaan apakah setiap varibel di relationship marketing yang telah diterapkan di Rumah Makan Patene memiliki pengaruh terhadap loyalitas konsumen baik secara serempak maupun parsial, sehingga peneliti melakukan penelitian ini dengan tujuan untuk menganalisis dan menguji apakah variabel relationship marketing yang diterapkan oleh Rumah Makan Patene terhadap loyalitas konsumen memiliki pengaruh secara serempak dan secara parsial. Hipotesis dari penelitian ini dapat dijabarkan sebagai berikut.

$\mathrm{H}_{1}$ : Understanding customer expectations memiliki pengaruh terhadap loyalitas konsumen

$\mathrm{H}_{2}$ : Building service partnership memiliki pengaruh terhadap loyalitas konsumen

$\mathrm{H}_{3}$ : Total quality management memiliki pengaruh terhadap loyalitas konsumen

$\mathrm{H}_{4}$ : Relationship marketing input yang terdiri dari understanding customer expectation, building service partnership, dan total quality management memiliki pengaruh secara serempak terhadap loyalitas konsumen

\section{METODE}

Dalam mengumpulkan data untuk penelitian ini, peneliti menggunakan instrumen penelitian yakni dengan melakukan pembagian kuesioner di mana peneliti memodifikasi indikator-indikator yang diterapkan oleh Evans \& Laskin (1994), Purwanto (2015), Borneo \& Sutopo (2011), serta Sarim dkk. (2013).

Tabel 1. Tabel definisi operasional

\begin{tabular}{|c|c|c|}
\hline Variabel & Definisi operasional & Indikator \\
\hline $\begin{array}{l}\text { Understanding } \\
\text { Customer } \\
\text { Expectation }\end{array}$ & $\begin{array}{l}\text { Suatu aktivitas di mana } \\
\text { perusahaan merekognisi } \\
\text { keinginan-keinginan atau } \\
\text { harapan-harapan yang dimiliki } \\
\text { oleh konsumen dan memasarkan } \\
\text { produk maupun jasa sesuai } \\
\text { dengan yang diinginkan atau } \\
\text { diharapkan oleh konsumen } \\
\text { (Anwar, 2016) }\end{array}$ & $\begin{array}{l}\text { - Karyawan memiliki sikap yang ramah } \\
\text { terhadap konsumen } \\
\text { - Karyawan memberikan informasi } \\
\text { kepada konsumen mengenai produk } \\
\text { - Karyawan sigap dalam melayani } \\
\text { konsumen } \\
\text { - Produk yang ditawarkan sesuai } \\
\text { dengan yang diharapkan oleh } \\
\text { konsumen } \\
\text { - Proses penyediaan produk cepat } \\
\text { - Produk yang ditawarkan bersih dan } \\
\text { aman } \\
\text { - Rumah makan secara aktif } \\
\text { mengumpulkan opini dari konsumen }\end{array}$ \\
\hline $\begin{array}{l}\text { Building Service } \\
\text { Partnership }\end{array}$ & $\begin{array}{l}\text { Suatu kerja sama yang dilakukan } \\
\text { oleh perusahaan bersama } \\
\text { konsumen untuk menambahkan } \\
\text { pelayanan yang diinginkan } \\
\text { konsumen (Sarim dkk., 2013) }\end{array}$ & $\begin{array}{l}\text { - Rumah makan mendengarkan dan } \\
\text { mengatasi keluhan konsumen } \\
\text { - Rumah makan melibatkan konsumen } \\
\text { dalam meningkatkan mutu } \\
\text { - Rumah makan menjalin komunikasi } \\
\text { dengan konsumen }\end{array}$ \\
\hline $\begin{array}{l}\text { Total Quality } \\
\text { Management }\end{array}$ & $\begin{array}{l}\text { Sebuah usaha dalam membentuk } \\
\text { kualitas perusahaan secara }\end{array}$ & $\begin{array}{l}\text { - Rumah makan memroduksi produk } \\
\text { yang berkualitas }\end{array}$ \\
\hline
\end{tabular}


hingga konsumen (Sarim dkk., 2013)

Loyalitas Konsumen

Sebuah dorongan sikap dalam melakukan transaksi secara berulang (Tangkilisan, 2013)
- Rumah makan memiliki kualitas pelayanan yang baik

- Rumah makan memiliki mutu yang baik

- Mutu dan kualitas pelayanan rumah makan lebih baik dibandingkan dengan rumah makan lainnya

- Rumah makan memiliki fasilitas yang bersih dan nyaman

- Karyawan memiliki kepercayaan diri saat melayani konsumen

- Cara kerja karyawan yang rapi

- Konsumen telah membeli produk lebih dari dua kali

- Konsumen merekomendasikan rumah makan kepada orang lain

- Konsumen tidak tertarik dengan rumah makan lainnya

- Konsumen yakin dan percaya bahwa pelayanan dan produk yang ditawarkan oleh rumah makan baik

Sumber: Evans \& Laskin (1994); Purwanto (2015); Borneo \& Sutopo (2011); serta Sarim dkk. (2013), dimodifikasi sesuai dengan kebutuhan penelitian

Pengukuran kuesioner menggunakan skala Likert. Skala Likert digunakan untuk mengukur sikap, pendapat, dan persepsi seseorang atau sekelompok orang tentang fenomena sosial (Sugiyono, 2013) di mana pengukuran nilai dari kuesioner adalah sebagai berikut.

Tabel 2. Skala penilaian

\begin{tabular}{llc}
\hline No. & Keterangan & Nilai \\
\hline 1. & Sangat Setuju & 5 \\
2. & Setuju & 4 \\
3. & Ragu-ragu & 3 \\
4. & Tidak Setuju & 2 \\
5. & Sangat Tidak Setuju & 1 \\
\hline
\end{tabular}

Sumber: Sugiyono (2013)

Populasi merupakan jumlah dari keseluruhan grup, orang, kegiatan, atau sesuatu yang ingin atau akan diteliti oleh peneliti di dalam sebuah penelitian (Sekaran \& Bougie, 2016). Di dalam penelitian yang dilakukan, populasinya adalah konsumen di Rumah Makan Patene dan melakukan transaksi di rumah makan lebih dari dua kali di mana pembelian yang berulang merupakan respon dari konsumen terhadap loyalitasnya (Evans \& Laskin, 1994).

Teknik pengambilan sampel adalah sebuah rangkaian proses di mana peneliti memilih individu, obyek, atau kejadian yang tepat dari sebuah populasi di mana akan menjadi representasi atau gambaran dari populasi tersebut. Penentuan sampel dari penelitian ini adalah dengan menggunakan rumus Slovin di mana berdasarkan perhitungan rumus, peneliti mendapatkan jumlah sampel yang diperlukan yakni sebanyak 211 orang. Karakteristik dari responden dijabarkan pada Tabel 3 yakni:

Tabel 3. Karakteristik responden

\begin{tabular}{lllr}
\hline No. & $\begin{array}{l}\text { Karaketeristik } \\
\text { responden }\end{array}$ & Keterangan & Jumlah \\
\hline 1. & Jenis kelamin & Pria & 141 \\
2. & Usia & Wanita & 70 \\
& & $31-40$ tahun & 25 \\
& & $41-50$ tahun & 48 \\
& & 51-60 tahun & 43 \\
& & $>60$ tahun & 23 \\
3. & Pekerjaan & Pegawai swasta & 118
\end{tabular}




\begin{tabular}{lr} 
Wirausahawan & 48 \\
Pegawai negeri & 5 \\
Lainnya & 40 \\
\hline
\end{tabular}

Sumber: Hasil pengolahan SPSS (2017)

Peneliti melakukan penelitian ini di Rumah Makan Patene yang terletak di Jalan Sulawesi No. 48 Makassar, Sulawesi Selatan dan telah berdiri sejak tahun 1975. Dalam melakukan pengujian, peneliti melakukan pengujian validitas dan reliabilitas terhadap kuesioner untuk memastikan valid dan reliabel tidaknya kuesioner yang dibagikan kepada responden, melakukan uji analisis regresi berganda, dan melakukan pengujian hipotesis yakni dengan uji serempak (Uji F) dan uji parsial (uji t). Peneliti tidak melakukan penelitian normalitas karena jumlah sampel yang diambil peneliti lebih dari 30 orang di mana apabila jumlah sampel melebihi 30 orang, maka dapat diasumsikan bahwa penelitian ini telah berdistribusi dengan baik dan pengujian distribusi normal tidak perlu dilakukan (Gravetter \& Wallnau, 2015). Pengujian ini menggunakan alat bantu software SPSS 22 agar menemukan hasil yang akurat.

\section{HASIL DAN PEMBAHASAN}

\subsection{Hasil}

Standar validitas dari variabel yang diteliti adalah $r>0,30$ (Sunjoyo, Setiawan, Carolina, Magdalena, \& Kurniawan, 2013), sehingga apabila nilai $r>0,30$, maka indikator tersebut dikatakan valid dan dapat digunakan untuk penelitian. Dari hasil yang ditampilkan pada Tabel 4, dapat dilihat bahwa seluruh nilai korelasi bivariate $>0,30$. Hal ini menunjukkan bahwa setiap indikator valid.

Tabel 4. Hasil uji validitas

\begin{tabular}{|c|c|c|c|}
\hline $\begin{array}{l}\text { Variabel/ } \\
\text { indikator }\end{array}$ & $\begin{array}{l}\text { Variabel } \\
\text { pertanyaan }\end{array}$ & $\begin{array}{l}\text { Korelasi } \\
\text { bivariate }\end{array}$ & Status \\
\hline \multirow[t]{7}{*}{ UCE (X1) } & X1.1 & 0,606 & Valid \\
\hline & $\mathrm{X} 1.2$ & 0,543 & Valid \\
\hline & X1.3 & 0.508 & Valid \\
\hline & X1.4 & 0,554 & Valid \\
\hline & X 1.5 & 0,514 & Valid \\
\hline & X1.6 & 0,538 & Valid \\
\hline & $\mathrm{X} 1.7$ & 0,654 & Valid \\
\hline \multirow{3}{*}{$\mathrm{BSP}(\mathrm{X} 2)$} & X2.1 & 0,911 & Valid \\
\hline & $\mathrm{X} 2.2$ & 0,842 & Valid \\
\hline & $\mathrm{X} 2.3$ & 0,435 & Valid \\
\hline \multirow[t]{7}{*}{ TQM (X3) } & X3.1 & 0,713 & Valid \\
\hline & X 3.2 & 0,717 & Valid \\
\hline & X3.3 & 0,716 & Valid \\
\hline & X3.4 & 0,316 & Valid \\
\hline & X3.5 & 0,634 & Valid \\
\hline & X3.6 & 0,855 & Valid \\
\hline & X3.7 & 0,314 & Valid \\
\hline \multirow{4}{*}{ LK $(\mathrm{Y})$} & Y 1.1 & 0,643 & Valid \\
\hline & $\mathrm{Y} 1.2$ & 0,751 & Valid \\
\hline & Y 1.3 & 0,497 & Valid \\
\hline & Y1.4 & 0,836 & Valid \\
\hline
\end{tabular}

Sumber: Hasil pengolahan SPSS (2017)

Tabel 5. Hasil uji reliabilitas

\begin{tabular}{lcc}
\hline $\begin{array}{l}\text { Variabel/ } \\
\text { indikator }\end{array}$ & $\begin{array}{l}\text { Cronbach's } \\
\text { alpha }\end{array}$ & Status \\
\hline UCE (X1) & 0,622 & Reliabel \\
BSP (X2) & 0,614 & Reliabel \\
TQM (X3) & 0,693 & Reliabel \\
LK (Y) & 0,617 & Reliabel \\
\hline
\end{tabular}

Sumber: Hasil pengolahan SPSS (2017) 
Standar reliabel dari variabel yang diteliti adalah nilai cronbach's alpha $>0,60$ (Sunjoyo dkk., 2013). Dapat dilihat di Tabel 5, yakni hasil uji reliabilitas, bahwa seluruh nilai cronchbach's alpha > 0,60 , sehingga dapat disimpulkan bahwa indikator yang digunakan adalah reliabel.

Tabel 6. Hasil analisis regresi berganda dan uji t

\begin{tabular}{lccccc}
\hline \multirow{2}{*}{$\begin{array}{l}\text { Variabel/ } \\
\text { indikator }\end{array}$} & \multicolumn{2}{c}{ Cronbach's alpha } & $\begin{array}{c}\text { Standard } \\
\text { coefficients }\end{array}$ & $\mathrm{t}$ & Sig \\
\cline { 2 - 3 } & $\mathrm{B}$ & Std. error & & \\
\hline (Constant) & 0,885 & 0,280 & & 3,164 & 0,002 \\
UCE (X1) & 0,201 & 0,043 & 0,259 & 4,634 & 0,000 \\
BSP (X2) & 0,331 & 0,053 & 0,364 & 6,250 & 0,000 \\
TQM (X3) & 0,277 & 0,062 & 0,261 & 4,455 & 0,000 \\
\hline
\end{tabular}

Sumber: Hasil pengolahan SPSS (2017)

Persamaan regresi berganda yang dihasilkan dari Tabel 6 adalah:

$$
\mathrm{Y}=0,885+0,201 \mathrm{X} 1+0,331 \mathrm{X} 2+0,277 \mathrm{X} 3
$$

Persamaan di atas memerlihatkan bahwa variabel-variabel dari relationship marketing memiliki nilai yang positif terhadap loyalitas konsumen dengan nilai 0,885 sebagai nilai konstan. Tabel 6 memerlihatkan hasil uji parsial atau uji t dari variabel-variabel relationship marketing, di mana berdasarkan standar signifikansi, variabel akan dikatakan memiliki pengaruh apabila memiliki nilai signifikan kurang dari atau $<0,05$, di mana melalui data yang ditampilkan, dapat dilihat bahwa variabelvariabel independent (relationship marketing) berada di bawah 0,05 atau sesuai dengan standar signifikansi. Hal ini menunjukkan bahwa variabel-variabel tersebut memiliki pengaruh nyata terhadap variabel dependent (loyalitas konsumen).

Tabel 7. Hasil analisis uji serempak

\begin{tabular}{lrrr}
\hline Model & df & F & Sig \\
& & & \\
\hline $\begin{array}{l}\text { Regression } \\
\text { Residual }\end{array}$ & 3 & 41,019 & $0,000^{\mathrm{b}}$ \\
Total & 207 & & \\
\hline Sula & 210 & & \\
\hline
\end{tabular}

Sumber: Hasil pengolahan SPSS (2017)

Hasil uji serempak (uji F) dapat dilihat di dalam Tabel 7, di mana variabel independent secara serempak dinyatakan memiliki pengaruh yang signifikan dan secara serempak apabila nilai di kolom signifikansi $<0,05$. Nilai signifikansi yang ditunjukkan dalam Tabel 7 adalah 0,000 , yakni $<0,05$, sehingga melalui data tersebut dapat dilihat bahwa variabel-variabel yang terdapat di dalam relationship marketing yang diteliti secara bersamaan memiliki pengaruh yang signifikan terhadap loyalitas dari konsumen.

\subsection{Pembahasan}

Melalui data-data yang ditampilkan, maka hasil penelitian yang ada memerlihatkan bahwa setiap variabel yang ada di dalam relationship marketing yang diterapkan oleh Rumah Makan Patene memiliki pengaruh secara parsial dan serempak atas loyalitas konsumen di sana. Selain itu, hasil juga menunjukkan bahwa pengaruh yang dimiliki adalah pengaruh yang positif. Nilai relationship marketing input, yakni building service partnership, memiliki nilai terbesar yakni sebesar 0,331 dibandingkan dengan relationship marketing input lainnya, yakni understanding customer expectations, di mana memiliki nilai sebesar 0,201 dan total quality management yang memiliki nilai sebesar 0,277. Ini menunjukkan bahwa building service partnership memiliki pengaruh yang lebih besar dibandingkan dengan variabel lainnya.

Temuan dari penelitian ini memiliki kesamaan dengan temuan dari penelitian yang dilakukan oleh beberapa ahli sebelumnya, yakni Evans \& Laskin (1994); Purwanto (2015); Borneo \& Sutopo (2011); Junistyaningrum \& Sugiarto (2016); dan Fakhrudin (2018). Hasil ini menunjukkan bahwa relationship marketing yang diterapkan di dalam Rumah Makan Patene memiliki pengaruh terhadap loyalitas dari 
konsumen, namun demikian, relationship marketing yang diterapkan oleh Rumah Makan Patene kurang efektif, di mana meski terdapat konsumen yang loyal dan membeli produk di Rumah Makan Patene lebih dari dua kali, jumlah konsumen yang berkunjung ke Rumah Makan Patene sendiri mengalami penurunan sehingga Rumah Makan Patene perlu melakukan pembaharuan atau pengembangan atas relationship marketing yang diterapkannya, seperti semakin melibatkan konsumen dan meminta feedback dari konsumen, semakin meningkatkan mutu dan kualitas produk dan pelayanan, serta mencari tahu tren-tren terbaru di saat sekarang ini untuk mengetahui selera konsumen yang berubah-rubah, mengingat bahwa Rumah Makan Patene sendiri tidak melakukan pembaharuan terhadap produk yang ditawarkan selama beberapa tahun terakhir.

\section{SIMPULAN DAN SARAN}

Melalui data dan pembahasan yang telah dan dipaparkan sebelumnya, maka peneliti dapat menarik beberapa simpulan:

1. Understanding Customer Expectation (UCE) memiliki pengaruh terhadap loyalitas konsumen Rumah Makan Patene.

2. Building Service Partnership (BSP) memiliki pengaruh terhadap loyalitas konsumen Rumah Makan Patene.

3. Total Quality Management memiliki pengaruh terhadap loyalitas konsumen Rumah Makan Patene.

4. Relationship marketing input di Rumah Makan Patene, yakni yang terdiri dari understanding customer expectation (UCE), building service partnership (BSP), dan total quality management $(T Q M)$ memiliki pengaruh secara serempak terhadap loyalitas konsumen.

5. Relationship markting input yang diterapkan di dalam Rumah Makan Patene memiliki pengaruh terhadap loyalitas konsumen, namun kurang efektif. Hal ini dapat dilihat melalui jumlah konsumen di Rumah Makan Patene yang mengalami penurunan.

Melalui data dan simpulan, maka terdapat beberapa saran yang dapat diberikan peneliti yakni sebagai berikut.

1. Setiap variabel atau indikator dalam relationship marketing input sebaiknya terus diterapkan dan ditingkatkan, seperti meningkatkan mutu dan kualitas produk dan pelayanan serta mengikuti trentren terbaru sehingga dapat meningkatkan loyalitas konsumen dan mempertahankan konsumen.

2. Rumah Makan Patene sebaiknya semakin mengembangkan relationship marketing dengan cara meminta feedback dari konsumen mengenai kualitas dan mutu produk dan pelayanan sehingga dapat meningkatkan dan mempertahankan konsumen serta mendapatkan konsumen yang baru, mengingat semakin ketatnya persaingan di dunia global saat ini, terutama persaingan dalam usaha rumah makan di mana semakin banyaknya rumah makan yang bermunculan dan building service partnership di mana menjalin hubungan dengan konsumen merupakan variabel yang memiliki pengaruh yang paling besar di dalam membangun loyalitas konsumen.

3. Untuk penelitian selanjutnya, peneliti sebaiknya melakukan penelitian mengenai pengaruh relationship marketing input terhadap perusahaan atau usaha lainnya, seperti usaha manufaktur, agar mengetahui berbagai macam pengaruh relationship marketing input dari berbagai industri.

\section{ACKNOWLEDGEMENTS}

Artikel ini merupakan bagian dari skripsi "Pengaruh Relationship Marketing terhadap Loyalitas Konsumen di Rumah Makan Patene di Makassar" oleh Lisa Jolanda Catherine Polimpung di Universitas Atma Jaya Makassar pada tahun 2017. 


\section{REFERENSI}

Anwar. (2016). Kajian implementasi relationship marketing terhadap customer loyalty (loyalitas mahasiswa (Kasus pada Fakultas Ekonomi Universitas Muhammadiyah Jember). Jurnal Manajemen dan Bisnis Indonesia, 2(2), 46-57. Diperoleh dari http://jurnal.unmuhjember.ac.id/index.php/JMBI/article/view/450/343.

Borneo, K., \& Sutopo, S. (2011). Pengaruh implementasi relationship marketing terhadap loyalitas konsumen pada produk oli pelumas PT Pertamina (PERSERO) Enduro 4T. Jurnal Ekonomi, 1(1), 127. Diperoleh dari http://eprints.undip.ac.id/27853/1/Jurnal_Kumbokarno.pdf.

Evans, J. R., \& Laskin, R. L. (1994). The relationship marketing process: A conceptualization and application. Industrial Marketing Management, 23, 439-452. Diperoleh dari https://www.academia.edu/34854111/The_Relationship_Marketing_Process_A_Conceptualization _and_Application.

Fakhrudin, A. (2018). Persepsi pelanggan terhadap implementasi relationship marketing pada Waroeng Sambal Yogyakarta. Jurnal Manajemen Bisnis, 9(2), 116-137. Diperoleh dari: https://journal.umy.ac.id/index.php/mb/article/view/5400/4041.

Gravetter, F. J., \& Wallnau, L. B. (2015). Statistic for the behavioral sciences. Canada: Cengagae Learning.

Haruna, S. (1997). The implementation of relationship process by Bauraq: The customer's perspective. Kelola Gadjah Mada University Business Review, 15(4), 24-37. Diperoleh dari http://ilib.ugm.ac.id/jurnal/detail.php?dataId=7807.

Junistyaningrum, N., \& Sugiarto, Y. (2016). Pengaruh implementasi relationship marketing terhadap customer loyalty dengan customer satisfaction sebagai variabel intervening. Diponegoro Journal of Management, $5(1), \quad 1-14 . \quad$ Diperoleh dari https://ejournal3.undip.ac.id/index.php/djom/article/view/13452/13008.

Kompasiana (2011, Februari 15). Kualitas Produk VS Kepuasan Pelanggan. Diperoleh dari https://www.kompasiana.com/hadi_santa/55008503a333115b73511120/kualitas-produk-vskepuasan-pelanggan.

Kotler, P., \& Armstrong, G. (2016). Principle of marketing. New Jearsey: Pearson.

Kotler, P., \& Keller, K. L. (2014). Marketing management. Global Edition, Edisi Lima Belas, Jilid 1. England: Pearson Education Limited.

Purwanto, A. B. (2015). Pengaruh service performance dan relationship marketing terhadap loyalitas konsumen. Fokus Ekonomi 10(1), 88-101. Diperoleh dari https://ejournal.stiepena.ac.id/index.php/fe/article/view/75/72.

Rahmawati, N. Y. (2016). Pengaruh relationship marketing terhadap loyalitas nasabah pada Bank Negara Indonesia (Persero) Tbk. cabang Malang. Jurnal Ilmiah Mahasiswa FEB Universitas Brawijaya 1(2), 1-14. Diperoleh dari: https://jimfeb.ub.ac.id/index.php/jimfeb/article/view/380.

Saputri, J., Yaningwati F., \& Fanani D. (2013). Pengaruh implementasi relationship marketing terhadap loyalitas pelanggan (survei pada nasabah PT. XXX cabang Malang). Jurnal Administrasi Bisnis, 5(2), 1-7. Diperoleh dari http://administrasibisnis.studentjournal.ub.ac.id/index.php/jab/article/view/249.

Sarim, S., Setiawan A., \& Freddy, R. (2013). Pengaruh relationship marketing terhadap customer satisfaction dan customer loyalty. Jurnal Telematika 8(1), 15-21. Diperoleh dari https://journal.ithb.ac.id/telematika/article/view/66/96.

Sekaran, U., \& Bougie, R. (2016). Research methods for business. $7^{\text {th }}$ Edition. United Kingdom: Wiley.

Sugiyono. (2013). Metode penelitian manajemen: Pendekatan kuantitatif, kualitatif, kombinasi (mixed methods), penelitian tindakan (action research), penelitian evaluasi. Bandung: Alfa Beta.

Sunjoyo, Setiawan, R., Carolina, V., Magdalena, N., \& Kurniawan, A. (2013). Aplikasi SPSS untuk smart riset: Program IBM SPSS 21. Bandung: Alfa Beta.

Tangkilisan, F. G. (2013). Relationship marketing: Pengaruhnya terhadap customer loyalty pada PT. Bank Perkreditan Rakyat Prisma Dana Manado. Jurnal EMBA, 1(4), 224-233. Diperoleh dari https://media.neliti.com/media/publications/1775-ID-relationship-marketing-pengaruhnyaterhadap-customer-loyalty-pada-pt-bank-perkre.pdf. 